\title{
CONSTRUCTION AND PERFORMANCE EVALUATION A SIMPLE UNIT FOR MASH COMPOST PELLETING
}

\author{
El-Shal, M. S. ${ }^{1}$ \\ M. M. A. El-Sharabasy ${ }^{2}$ \\ S. E. El-Taher ${ }^{3}$
}

\section{ABSTRACT}

Compost is considered an important source for agricultural fertilization, because it contains a high level of nutrients and organic matter. The compost is produced from different agricultural wastes and some additives like water and animal poultry residues. In this study, experiments were conducted to optimize some engineering and operating parameters affecting the performance of disk pelleting machine. The parameters under this study were four different roller rotating speeds of 175, 225, 275 and $325 \mathrm{rpm}$; four different die profiles of DieA (18.8 mm land length with $13.5 \mathrm{~mm}$ entry diameter), Die-B $(20.3 \mathrm{~mm}$ land length with $13.5 \mathrm{~mm}$ entry diameter), Die-C (18.8 mm land length with $14.2 \mathrm{~mm}$ entry diameter) and Die-D (20.3 mm land length with $14.2 \mathrm{~mm}$ entry diameter); four different compost raw martial moisture contents of (15, 20, 25 and 30\%) $w b$. The obtained results revealed that the pelleting machine has a high efficiency and maximum pellets quality under conditions of $20 \%$ compost raw material moisture content, 275rpm rollers speed and die profile (C) of $(18.8 \mathrm{~mm}$ land length with $14.2 \mathrm{~mm}$ entry diameter). The optimum results were $287.79 \mathrm{~kg} / \mathrm{h}$ pelleter productivity, $19.81 \mathrm{~kW} . \mathrm{h} / \mathrm{Mg}$ energy requirements, $93.68 \%$ pellets durability and 108.31 L.E/Mg cost per mass unit.

\section{INTRODUCTION}

gricultural wastes in Egypt compose of wood, maize cob, straw, and
rice straw. Sugar cane and beet wastes, vegetables and fruits wastes, all
equal to about 16 million ton yearly. (Abou-Akkada and Nour 1985). There are anther different types for agricultural wastes as follows: (1) Animal wastes: (blood-meat-stomach contents-feather), farms wastes (poultry and litter animal dung and urine), processing and marketing fish wastes and dairy factory wastes. (2) Plants wastes: farm wastes (stubble crops, wood, shopped straw) processing product waste of vegetables fruits and crops (straws, gluten, oilseeds crust, wastes of canning, and drying the vegetables such as potato, pea, onion carrots and fruits like citrus, peanut peeling, molasses, sugar beet bulb) and several markets waste beside weeds and moss see.

\footnotetext{
${ }_{1}^{1}$ Prof. of Ag. Eng. Dept., Fac. of Ag., Zagazig Univ., Egypt.

${ }^{2}$ Assist. Prof. of Ag. Eng. Dept., Fac. of Ag., Zagazig Univ., Egypt.

${ }^{3}$ Post graduate student, Ag. Eng. Dept., Fac. of Ag., Zagazig Univ., Egypt.
} 
(3) Mixture wastes: as restaurants and kitchen wastes. (4) Creative wastes: as urea, ammonia and its salts, and (5) Cereal wastes: as maize and wheat. (Nour, 1988). Greer and Fairchild (1999) found that the moisture in feed mash affects pellets quality and production rates. Moisture in feed mash comes from two sources: bound moisture present in the feeds ingredients and added moisture from water and steam addition. The moisture of cold feed entering the conditioner limits the amount of steam that can be added to the mash during conditioning. Bhienki (2000) decreasing the particle size of ingredients dial to a greater surface area to volume ratio. Smaller particles will have a greater number of contact points within a pellet matrix as compared to larger particles. Ismael (2001) mentioned that the most popular source of plant wastes is the crop field wastes, the food processing wastes and the wastes of restaurants and human houses. In fact, since thousands of years ago 'man had used the plant wastes in manufacturing paper and woods, polishing materials. Also, these wastes are used as a partial substitution to petroleum as a source of energy by producing biogas the agriculture wastes are also used in animal feeding. David (2003a) mentioned that understanding the terminology used to describe dies is important when choosing die specifications, different feed and ingredients require specific amounts of time in the die hole-die retention time-to be able to bind together to form a pellet. Larger die working areas provide more retention time to form pellets, reduce power consumption per ton of feed pelleted and improve production efficiencies. David (2003b) reported that the LD ratios is the effective length of die divided by the hole diameter, high $\mathrm{L} / \mathrm{d}$ ratio provide a high pellet die resistance as feed moves through the hole while the low L/D ratios provide less resistance. Each material has one $\mathrm{L} / \mathrm{d}$ ratio requirement to form the material into pellet. He also, illustrated the terminology used to describe the characteristics and dimensions of die holes. The most important terms to understand when selecting a pellet die are: $\mathrm{D}=$ Hole diameter: Typical hole diameter can range from 3/32nd to 3/4th inch. $\mathrm{L}=$ Effective length: The effective length is the die thickness that actually performs work on the feed. L/D ratio: The L/D ratio is the effective length divided by the hole diameter. The pellets quality is dependent upon several factors:(1) feed formulation, (2) feed particle size, (3) mash moisture content, (4) conditioning, (5) die specifications and (6) cooling. Hasting (2003) determined the operating conditions affecting the quality of pellets feed as follows: pellet die thickness as related to diameter of 
hole is factor in pelleted quality, speed of ration should be also considered for each die thickens/hole diameter combination. Jennifer (2004) reported that the durability of the pellets form poultry litter varied form about 28 to $46 \%$ within a moisture content range of $6.0 \%$ to $22.2 \%$ w.b. Durability of the pellets increased initially with moisture content reaching a maximum at $10.4 \%$. Further increase in moisture content reduced durability. The subsequent increase in volume of the pellets due to increased moisture content was not sufficient to offset these binding forces. Pellets hardness was a more sensitive to moisture change than pellet durability. Absorbed moisture decreased the strength of bonds holding the pellet particles together thus making the pellets more friable. The force required to rupture the pellets varied from $350 \mathrm{~N}$ at $6.0 \%$ moisture to $50 \mathrm{~N}$ at $22.0 \%$ w.b. temperature of the pellets exiting the die increased to $85^{\circ} \mathrm{C} \pm 2^{\circ} \mathrm{C}$ after pelleting, the pellets were cooled in an environmental chamber set at $22^{\circ} \mathrm{C}$ and $40 \%$ relative humidity. Hara (2005) mentioned that in the disk pelleter or extruder, the moisture content of compost is most important factor. It greatly influences the strength and processing speed of the pellet. The best moisture content is about $40 \%$ for an extruder and about $20-25 \%$ for disc pelleter. The fluidity of compost falls with a lower moisture content and friction resistance increases as the compost passes through the holes of the die. Shehab et al. (2005) found that the operation of the majority of current pellet mills is based on pressing the material through open-ended holes (dies) built in the periphery of a rotating ring die. Depending upon the design, one to three smaller rolls push the feed material into the die holes from inside of the ring towards outside of it. The skin direction between the feed particles and the wall of the die resists the free flow of feed and thus, the particles are compressed against each other inside the die. The compressed feed traveled through the die continuously. The pellets are cut into preset lengths using a knife. Kaddour et al. (2006) mentioned that geometrical dimensions of die holes reference the most important factors influencing in extruder machine efficiency and pellets quality. Producing $12 \mathrm{~mm}$ diameter high quality of large animal feed pellets rely the ration components attributes, for that the high quality extruded pellets made from residues need different die hole specification comparing with that made from standard components. The optimum machine efficiency appraised by machine productivity, energy requirements and total losses and appraised for pellets quality by pellets durability, pellets bulk density, and pellets hardness. Results were obtained using 
L/D ratio of 1.67 hole entry diameter of $20 \mathrm{~mm}$, output area percent of $2.66 \%$ and $35 \mathrm{~mm}$ total thickness, resulting in $0.3058 \mathrm{Mg} / \mathrm{h}$ productivity, $153.10 \mathrm{~kW} . \mathrm{h} / \mathrm{Mg}$ energy requirement, $5.38 \%$ total losses, $90.35 \%$ durability, $1.1109 \mathrm{~g} / \mathrm{cm}^{3}$ bulk density, and $170.11 \mathrm{~N} / \mathrm{cm}^{2}$ strength. So, this work aimed to fabricate, assembly and evaluate a simple unit for compost pelleting crops residues.

\section{MATERIALS AND METHODS}

\subsection{MATERIALS:}

\subsubsection{Experimental compost raw material:}

The mash compost which used in this study was produced by Sharkia company in Belbees city. This compost is produced from different agricultural wastes and some additives like water and animal poultry residues. The final moisture content of Sharkia compost is ranged from 20 to $25 \%$ at maturity. The chemical analyses of compost raw materials is shown in Table 1.

Table 1. Composition and chemical analyses of mash compost.

\begin{tabular}{lcc}
\hline \multicolumn{1}{c}{ Composition } & Value & Unit \\
\hline Density & 650 & $\mathrm{~kg} / \mathrm{m}^{3}$ \\
Moisture content & 22 & $\%$ \\
PH (10: 1) & 7.91 & --- \\
EC (10: 1) & 3.47 & $\mathrm{Ds} / \mathrm{m}$ \\
Ammonium nitrogen & 6.4 & $\mathrm{ppm}$ \\
Nitration nitrogen & 38 & $\mathrm{ppm}$ \\
Total nitrogen & 1 & $\%$ \\
Organic matter & 33.2 & $\%$ \\
Organic carbon & 19.3 & $\%$ \\
Ash & 66.8 & $\%$ \\
C/N Ratio & $1: 19.3$ & --- \\
Total phosphoric & 0.54 & $\%$ \\
Total potassium & 0.78 & $\%$ \\
Grass seeds & 0.00 & $\%$ \\
\hline
\end{tabular}

\subsubsection{Disk pelleter machine:}

The disk pelleter machine (flat die) is one kind of pelleting system which including ring die pelleting. The diameter of compost pellets which produced in this work was $10 \mathrm{~mm}$. The disk pelleter consists of the following parts:

- Feeding unit: The feeding unit is made from metal sheet which has thickness of $2 \mathrm{~mm}$ cylindrical shape to be a feeding hopper of pelleting machine. The feeding hopper has dimensions of $301.2 \mathrm{~mm}$ diameter and $500 \mathrm{~mm}$ height. 
- Forming unit (Die): The die is considered the most important part in disk pelleter and sensitivity at pelleting operation system. It is responsible formed a mash compost to compost pellet. Die is a disk metal made from hard steed 52 carbon with dimensions of $300 \mathrm{~mm}$ in diameter, $35.5 \mathrm{~mm}$ in thickness as shown in Fig. 1. The die is fixed on main base without motion and the main shaft passing from die center with the conic bearing which fixed inter the die. The hole configuration consists of two levels: the first level is a conical shape (entry) has diameter bigger than the output diameter (land length) which affects on pelleting operation, Fig. (2). In the present study, four dies were fabricated each one has different profile to study the influence of geometrical dimensions of dies profile on machine efficiency and pellets quality. Each die profile has working area of $60 \mathrm{~mm}$ width at the middle track surface of the die face. This working area has a different number of holes depends on dies profile and this holes configuration between dies and due to entry diameter and died area between each hole.

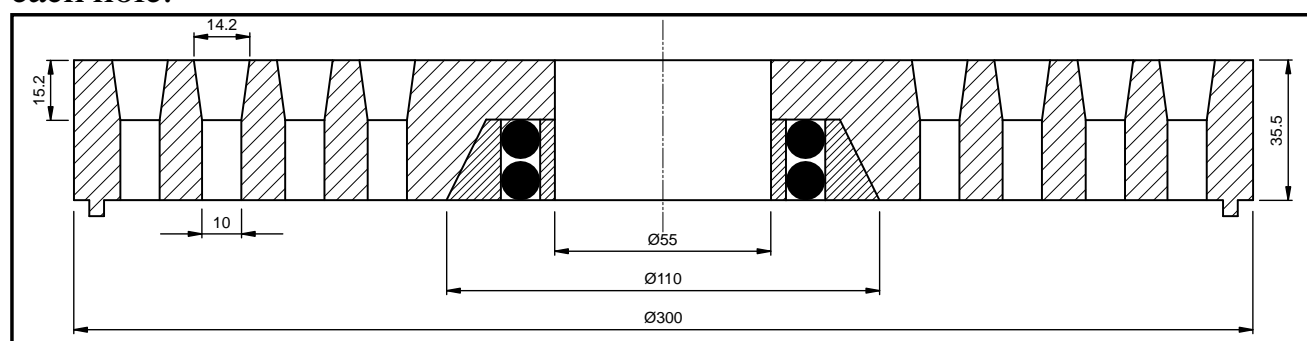

Fig.1: Longitudinal section of the die.

Dim. in, mm

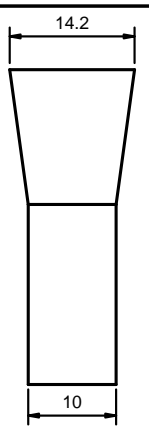

(D)

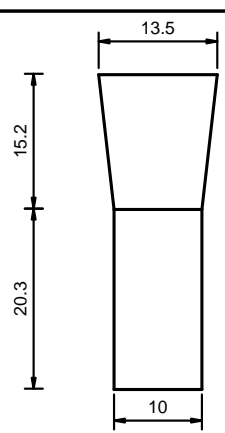

(B)

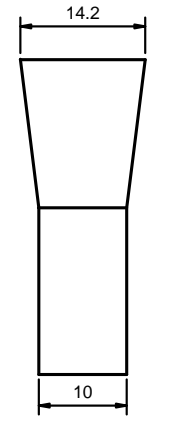

(C)

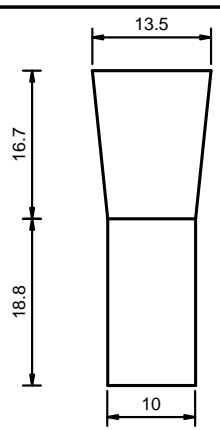

(A)

Fig.2: Die profiles (holes dimensions).

Dim. in, mm

- Compressing unit (Rollers): It's clear to know that the rollers were responsible of compressing and pelleting the mash compost through die rollers. The rollers consist of two units, each unit constructed on horizontal bar by 
conical bearings . This horizontal bar is fixed on the end of main moving shaft. Each roller has cylindrical shape with dimensions of 100mm diameter and 60 $\mathrm{mm}$ width has gearing shape in external surface which fabricated from hard steel 52 carbon. The animation of rollers has stable motion around horizontal bar which yields from the main shaft speed. There is clearance between die and rollers very narrow and extended according to physical motion rolls around horizontal bar to agree with a capacity of row materials forced pressing through die holes. There are two scraper bars (u) shapes, each one has dimension of $200 \times 30 \times 50 \mathrm{~mm}$ to distributing the input raw material in the front of the rollers and its fixed in rollers base. Fig. 3 .

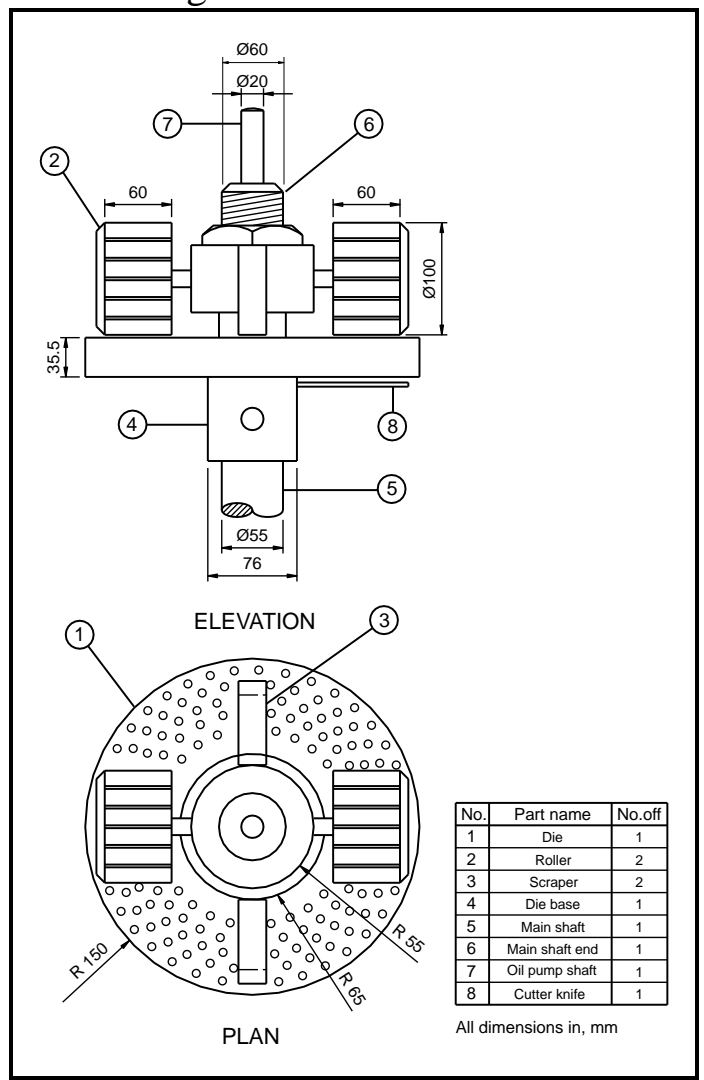

\section{Fig. 3. Elevation and plan of compressing unit (Rollers).}

- Electric motor and power transmission: An electrical motor has output (20 hp, $14.7 \mathrm{~kW}$ ) and $22 \mathrm{~A}$ was used. The rolling speed of motor shaft is $1400 \mathrm{rpm}$, reduced to $175,225,275$ and $325 \mathrm{rpm}$ at main shaft using 7:1 gearbox. The power is transmitted from the motor shaft through four different pulleys having diameters of $(7,9,11$ and $13 \mathrm{~cm})$ to gear box having pulley of $8 \mathrm{~cm}$ in diameter using $\mathrm{V}$ belts as shown in Fig.4. 


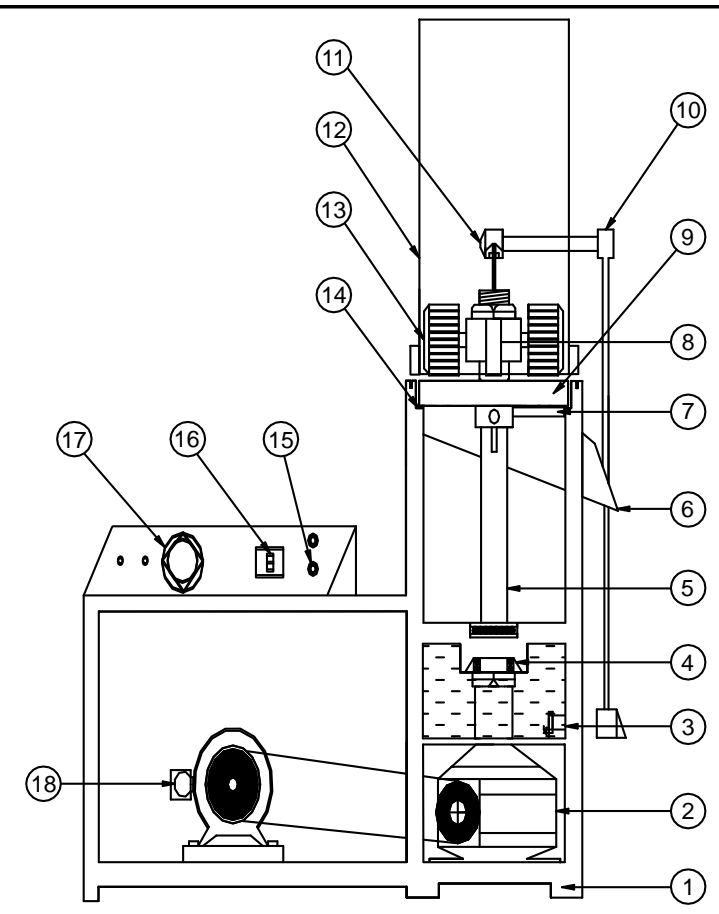

\begin{tabular}{|c|c|c|c|c|c|}
\hline No. & Part name & No. & Part name & No. & Part name \\
\hline 1 & Main base & 7 & Cutter knife & 13 & Compression roller \\
\hline 2 & Vertical gear box & 8 & Scraper bar & 14 & Die base \\
\hline 3 & Oil pump & 9 & Die & 15 & Indicator lamp \\
\hline 4 & Main bearing & 10 & Oil pipe & 16 & Motor switch \\
\hline 5 & Main shaft & 11 & Main shaft end & 17 & Motor amber \\
\hline 6 & Output pellet & 12 & Feeding hopper & 18 & Electrical motor \\
\hline
\end{tabular}

Fig.4. Disk pelleter layout and main motor.

- The main shaft: The main shaft was fixed in a vertical position to transfer power from the gearbox which contacted with electrical motor to rollers. It was fabricated from hard steel 52 carbon. The main shaft has dimension of $650.7 \mathrm{~mm}$ length, four levels of diameters $(35,45,55$ and $60 \mathrm{~mm})$. Main shaft is fixed by three bearings, conical bearing is fixed in the die center, another is fixed in the oil chamber and surface bearing in the middle and shaft passing from its end by rollers units. There are gear box constructed on the main base under main shaft and contacted by it.

- Cooling system: In this type of disk pelleter, the rollers motion generated quantity of heat. For this the cooling system was a very important. Cooling system consists of oil tank, oil pump and tubs ending by nozzle at the end of main shaft for close system during shaft hole. Cooling system transfer oil from the oil tank to the main shaft and cooling it. 
- Cutter knife: Cutter knife is made from stainless steel 37 carbon with dimension of $120 \mathrm{~mm}$ in length and $5 \mathrm{~mm}$ in thickness. The cutter knife is fixed on the main shaft directly under the die and can change the number of knifes to change the product length. It is a single knife and takes its motion from the main shaft rotating speed.

\subsection{METHODS:}

In this study, a disk pelleting machine was fabricated and assembled in a local workshop to produce compost pellets at Sharkia governorate, Zagazig city. Experiments were conducted to optimize some operational and engineering parameters affecting the performance of disk pelleting machine. The experimental groups named $\mathrm{A}, \mathrm{B}$ and $\mathrm{C}$.

A- The first group of tests was run under four different roller rotating speeds of $(175,225,275$ and $325 \mathrm{rpm})$.

B- The second group of tests was carried out under four different die profiles of:

- Die - A (18.8 mm land length with $13.5 \mathrm{~mm}$ entry diameter).

- Die - B (20.3 mm land length with $13.5 \mathrm{~mm}$ entry diameter).

- Die - C (18.8 mm land length with $14.2 \mathrm{~mm}$ entry diameter).

- Die - D (20.3 mm land length with $14.2 \mathrm{~mm}$ entry diameter).

C- The third group of tests was conducted under four different mash compost moisture contents of $(15,20,25$ and 30\%) w.b.

\subsection{MEASUREMENTS:}

- Disk pelleter productivity:

$$
\text { Disk pelleterproductivity }=\frac{\mathrm{W}_{\mathrm{P}}}{\mathrm{T}} \times 3.6, \mathrm{~kg} / \mathrm{h}
$$

Where: $\mathrm{W}_{\mathrm{p}}$ : Pellets mass, $(\mathrm{g})$ and $\mathrm{T}$ : Consumed time, (s).

\section{- Pellets Durability:}

$$
\text { Durability }=\frac{\mathrm{Wa}}{\mathrm{Wb}} \times 100, \%
$$

Where: Wa: pellets mass after treatment, (g).

$\mathrm{Wb}$ : pellets mass before treatment, $(\mathrm{g})$.

\section{- Energy requirements:}

$$
\text { Energy Requirements }=\frac{\text { Engine power, }(\mathrm{kW})}{\text { Pelleter productivity, }(\mathrm{Mg} / \mathrm{h})}, \mathrm{kW} \cdot \mathrm{h} / \mathrm{Mg}
$$

- Compost pelleting cost: The compost pelleting operating cost was estimated using the following equation (Awady et al. 1982): 
PROCESS ENGINEERING

$$
\text { Operating cost }=\frac{\text { Machine } \operatorname{cost}(\mathrm{L} . \mathrm{E} / \mathrm{h})}{\text { Pelleter productivity },(\mathrm{Mg} / \mathrm{h})}, \quad(\mathrm{L} . \mathrm{E} / \mathrm{Mg})
$$

Where:

Machine cost was determined by using the following equation (Awady, 1978):

$$
\mathrm{C}=\frac{\mathrm{P}}{\mathrm{h}}\left(\frac{1}{\mathrm{a}}+\frac{\mathrm{i}}{2}+\mathrm{t}+\mathrm{r}\right)+(1.2 \text { W.S.F })+\frac{\mathrm{m}}{144}
$$

Where:

$\mathrm{C}=$ Hourly cost, L.E/h. $\quad \mathrm{P}=$ Price of machine, L.E.

$\mathrm{h}=$ Yearly working hours, $\mathrm{h} /$ year. $\quad \mathrm{a}=$ Life expectancy of the machine, $\mathrm{y}$.

$\mathrm{i}=$ Interest rate/year. $\quad 1.2=$ Factor accounting for lubrications.

$\mathrm{t}=$ Taxes, over heads ratio. $\quad \mathrm{W}=$ Engine power, $\mathrm{hp}$.

$\mathrm{r}=$ Repairs and maintenance ratio. $\quad \mathrm{F}=$ Fuel price, L.E/l.

$\mathrm{m}=$ Monthly average wage, $\mathrm{L} . \mathrm{E} \quad \mathrm{S}=$ Specific fuel consumption, $\mathrm{l} / \mathrm{hp} . \mathrm{h}$.

$144=$ Reasonable estimation of monthly working hours.

\section{RESULTS AND DISCUSSION}

\subsection{Effect of some engineering and operating parameters on disk pelleter compost productivity:}

\subsubsection{Effect of compost moisture content: depleted}

Fig. 5 shows that increasing compost moisture content from $15 \%$ to $20 \%$ increased the pelleter productivity by $1.17,1.21,1.16$ and $1.20 \%$ at roller speed of $175 \mathrm{rpm}$ by $1.11,1.16,1.10$ and $1.14 \%$, using roller speed of $225 \mathrm{rpm}$ by1.06, $1.09,1.05$ and $1.09 \%$ at roller speed of 275rpm and by1.01, 1.04, 1.01 and $1.04 \%$ at roller speed of $325 \mathrm{rpm}$, under die profile (A), respectively. The increased in machine productivity by increasing the compost moisture content from $15 \%$ to $20 \%$ my be due to the decrease in treatment consumed time by the easy flow of the compost material through the die holes resulting from low friction for material and die holes. While increase the compost moisture content from $20 \%$ to 25 and $30 \%$ decreased the pelleter productivity by 2.88 , and $11.62 \%, 2.72$ and $10.93 \%, 2.60$ and 10.41 and, 2.50 and $9.85 \%$ using die profile (A) and by 2.99 and $12.11 \%, 2.82$ and $11.35 \%, 2.69$ and $10.88 \%$ and, 2.55 and $10.28 \%$ using die profile (B) and by, 2.96 and 11.57\%, 2.71 and 10.97\%, 2.68 and $10.46 \%$ and, 2.55 and $9.81 \%$, using die profile (C) and by, 3.86 and $12.04 \%$, 2.81 and $11.38 \%, 2.77$ and $10.75 \%$ and, 2,54 and $10.15 \%$ using die profile (D) using roller speeds of 175, 225, 275 and $325 \mathrm{rpm}$, respectively. The decrease in machine pelleter productivity by increasing the compost moisture content from 15 to 25 and $30 \%$ could be due to the increase in formula viscosity because it's 
including high percentage of clay, that make the formula flow through the die holes very low, and increase the treatment consumed time.

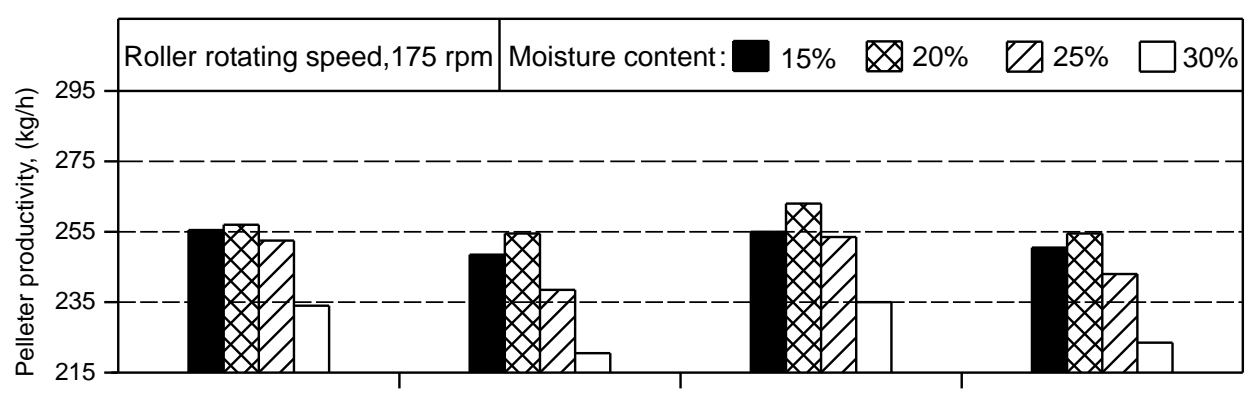

(A)

(B)

(C)

(D)

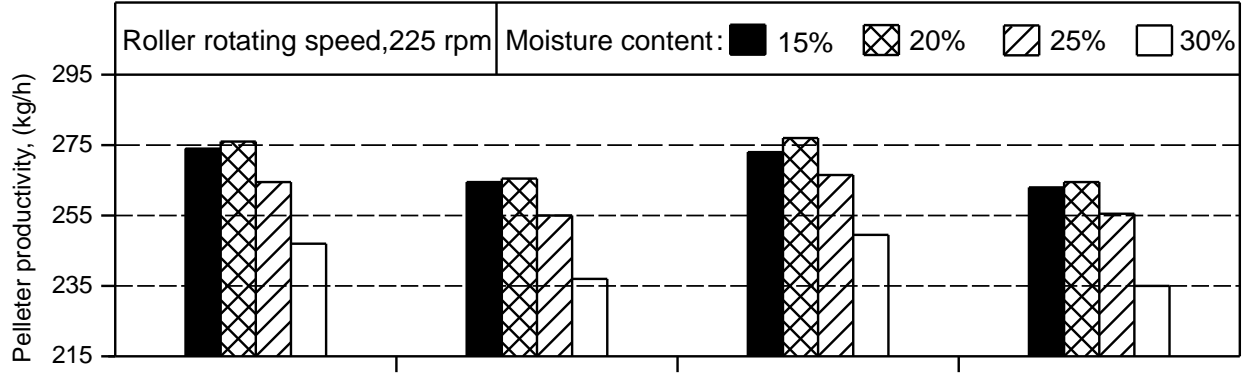

(A)

(B)

(C)

(D)

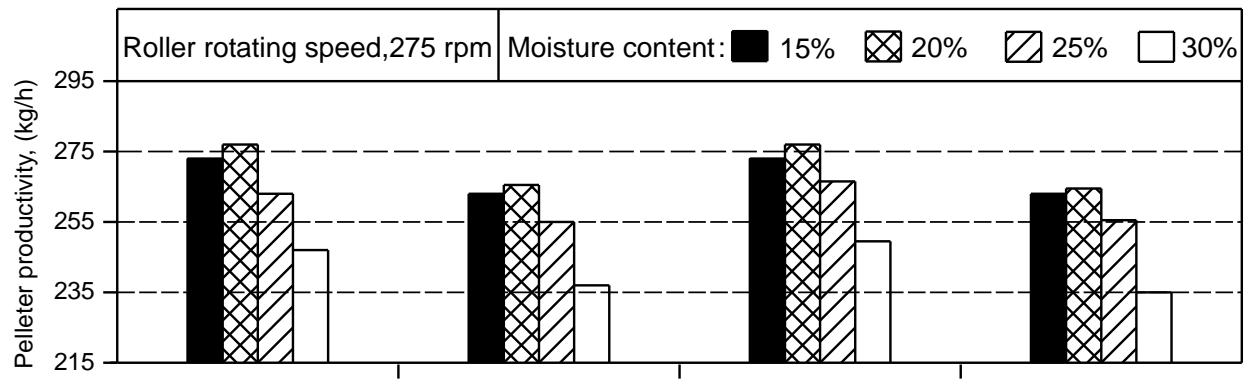

(A)

(B)

(C)

(D)

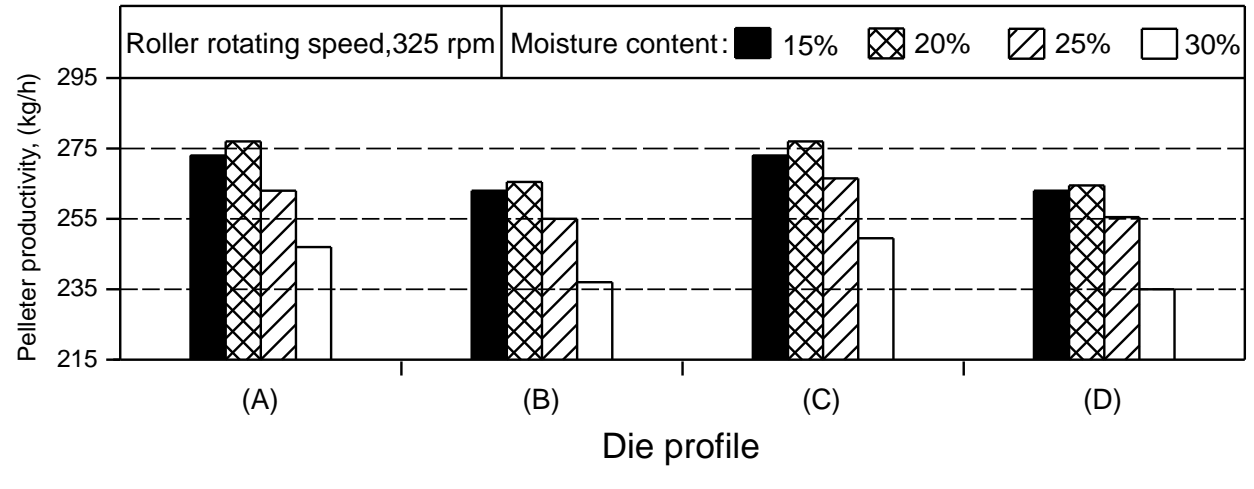

Fig. 5. Effect of die profile on disk pelleter production rate at different compost moisture contents and different rollers rotating speeds. 


\subsubsection{Effect of die profile:}

Results in Fig. 5 shows that changing the die holes profile from die (A) to die (B) and die (D) decreased the pelleter productivity by 3.69 and $3.26 \%$ at compost moisture content of $15 \% ; 3.65$ and $3.22 \%$ at compost moisture content of $20 \% ; 3.80$ and $3.35 \%$ at compost moisture content of $25 \% ; 4.14$ and $3.65 \%$ using compost moisture content of $30 \%$, and by 3.49 and $3.07 \%$ using compost moisture content of $15 \%, 3.45$ and $3.04 \%$ at compost moisture content of 20\%, 3.58 and $3.16 \%$ at compost moisture content of $25 \%$ and 3.88 and $3.42 \%$ using compost moisture content of $30 \%$, and by 3.33 and $2.94 \%$ at compost moisture content of $15 \%, 3.38$ and $2.91 \%$ at compost moisture content of $20 \%, 3.42$ and $3.02 \%$ using compost moisture content of $25 \%$ and 3.69 and $2.79 \%$ at compost moisture content of $30 \%$, and by 3.16 and $2.76 \%$ at compost moisture content of $15 \%, 3.13$ and $2.76 \%$ at compost moisture content of $20 \%, 3.24$ and $2.86 \%$ at compost moisture content of $25 \%$ and 3.48 and $3.07 \%$ at compost moisture content of $30 \%$ using roller speed of 175, 225, 275 and $325 \mathrm{rpm}$, respectively. The clear decrease in pelleter productivity by changing the die profile from (A) to (B) and (D) could be due to the increase in die hole land length, that make the compost raw material take more time in the die hole. On the other hand, changing the die profile from die (A) to die (C) increased the disk pelleter productivity by $0.38,0.37,0.39$ and $0.42 \%$ using roller speed of $175 \mathrm{rpm} .36$, $0.35,0.37$ and $0.39 \%$ at roller speed of $225 \mathrm{rpm}, 0.34,0.34,0.35$ and $0.37 \%$ at roller speed of $275 \mathrm{rpm}$ and by $0.33,0.32,0.34$ and $0.36 \%$ at roller speed of 325 rpm, under compost moisture content of $15,20,25$ and 30\%, respectively. The slow increase in pelleter productivity by changing the die profile from die (A) to die (C) could be due to the increase in die hole entry diameter, that make the compost raw material flow through the die hole easily and decrease slowly the consumed time.

\subsubsection{Effect of roller rotating speed:}

Data in Fig. 5 shows that, increasing the rollers speed from 175 to 225, 275 and $325 \mathrm{rpm}$ increased the pelleter productivity by $5.42 \%, 9.47$ and $13.91 \%$ at die profile (A), 5.54\%, 9.68 and $14.19 \%$ using die profile B, 5.34\%, 9.34 and $13.72 \%$ using die profile (C) and 5.58\%, 9.75 and $14.29 \%$ using die profile (D) under compost moisture content of 15\%, 5.36\%, 9.37 and $13.76 \%$ using die profile (A) 5.54\%, 9.68 and $14.20 \%$ using die profile (B) 5.34\%, 9.34 and $13.72 \%$ using die profile (C) and by $5.52 \%, 9.64$ and $14.14 \%$ using die profile (D) under compost moisture content of $20 \%, 5.56 \%, 9.72$ and $14.25 \%$ using die 
profile (A) $5.76 \%, 10.05$ and $14.71 \%$ using die profile (B) (20.3 mm land length with $13.5 \mathrm{~mm}$ entry diameter), 5.54\%, 9.68 and $14.20 \%$ using die profile (C) and $4.53 \%, 10.01$ and $14.65 \%$ using die profile (D) under compost moisture content of $25 \%$, and $6.00 \%, 10.46$ and $15.27 \%$ using die profile (A) $6.24 \%, 10.84$ and $15.81 \%$ using die profile (B) $5.98 \%, 10.42$ and $15.22 \%$ using die profile (C) and $6.21 \%, 10.8$ and $15.74 \%$ using die profile (D) under compost moisture content of $30 \%$. The increase in disk pelleter productivity by increasing the rollers speed from 175 to 225,275 and 325 could be due to the decrease in treatment consumed time of sample mass.

\subsection{Effect of some engineering and operating parameters on compost pellets durability:}

\subsubsection{Effect of compost moisture content:}

Fig. 6 shows that increasing compost moisture content from 15\% to $20 \%$ increased the pellets durability by $0.644,0.619,0.638$ and $0.617 \%$ at roller speed of $175 \mathrm{rpm}$, by $0.620,0.597,0.615$ and $0.596 \%$ at roller speed of $225 \mathrm{rpm}$ by $0.613,0.591,0.608$ and $0.589 \%$ using roller speed of $275 \mathrm{rpm}$ and by 0.604 , $0.583,0.599$ and $0.581 \%$ at roller speed of $325 \mathrm{rpm}$, under die profile of (A, B, $\mathrm{C}$ and $\mathrm{D})$, respectively. The increased in pellets durability by increasing the compost moisture content from $15 \%$ to $20 \%$ could be due to the increase in granules surface covered by water film that produce high hardness pellets after drying . While increase the compost moisture content from $15 \%$ to 25 and $30 \%$ decreased pellets durability by 2.41 , and $4.17 \%, 2.31$ and $4.00 \%, 2.29$ and 3.96 and, 2.26 and $3.90 \%$ at die profile (A) and by 2.31 , and $4.00 \%, 2.23$ and $3.85 \%$, 2.20 and 3.81 and, 2.17 and $3.75 \%$ using die profile (B) and by 2.39 , and $4.13 \%$, 2.29 and 3.97\%, 2.27 and 3.92 and, 2.23 and 3.86\% using die profile (C) and by 2.31, and 3.99\%, 2.22 and 3.84\%, 2.20 and 3.80 and, 2.17 and 3.74\% using die profile (D) at roller speeds of 175, 225, 275 and $325 \mathrm{rpm}$, respectively. The decrease in pellets durability by increasing the compost moisture content from 15 to 25 and $30 \%$ could be due to the increase in formula viscosity and the water film covered the compost granules that increase the air cells between the granules after drying, so increase the pellets cracks and decrease the pellets durability.

\subsubsection{Effect of die profile:}

Results in Fig. 6 shows that changing the die holes profile from die (A) to die (B), die (C) and die (D) increased the pellets durability by 3.78, 0.83 and $4.14 \%$, $3.76,0.82$ and $4.12 \%, 3.87,0.85$ and $4.24 \%$ and by $3.94,0.87$ and $4.31 \%$ at roller 
speed of $175 \mathrm{rpm}$, by 3.65, 0.80 and $3.99 \%, 3.62,0.79$ and $3.97 \%, 3.73,0.82$ and $4.08 \%$ and by $3.79,0.83$ and $4.15 \%$ at roller speed of $225 \mathrm{rpm}$, by 3.16, 0.79 and $3.95 \%, 3.58,0.79$ and $3.92 \%, 3.69,0.81$ and $4.04 \%$ and by $3.75,0.82$ and $4.10 \%$ using roller speed of $275 \mathrm{rpm}$, and by 3.56, 0.78and 3.89\%, 3.54,0.77 and $3.87 \%, 3.64,0.80$ and $3.97 \%$ and by $3.69,0.76$ and $4.04 \%$ at roller speed of 325 rpm, under compost moisture contents of 15, 20, 25 and 30\%, respectively.
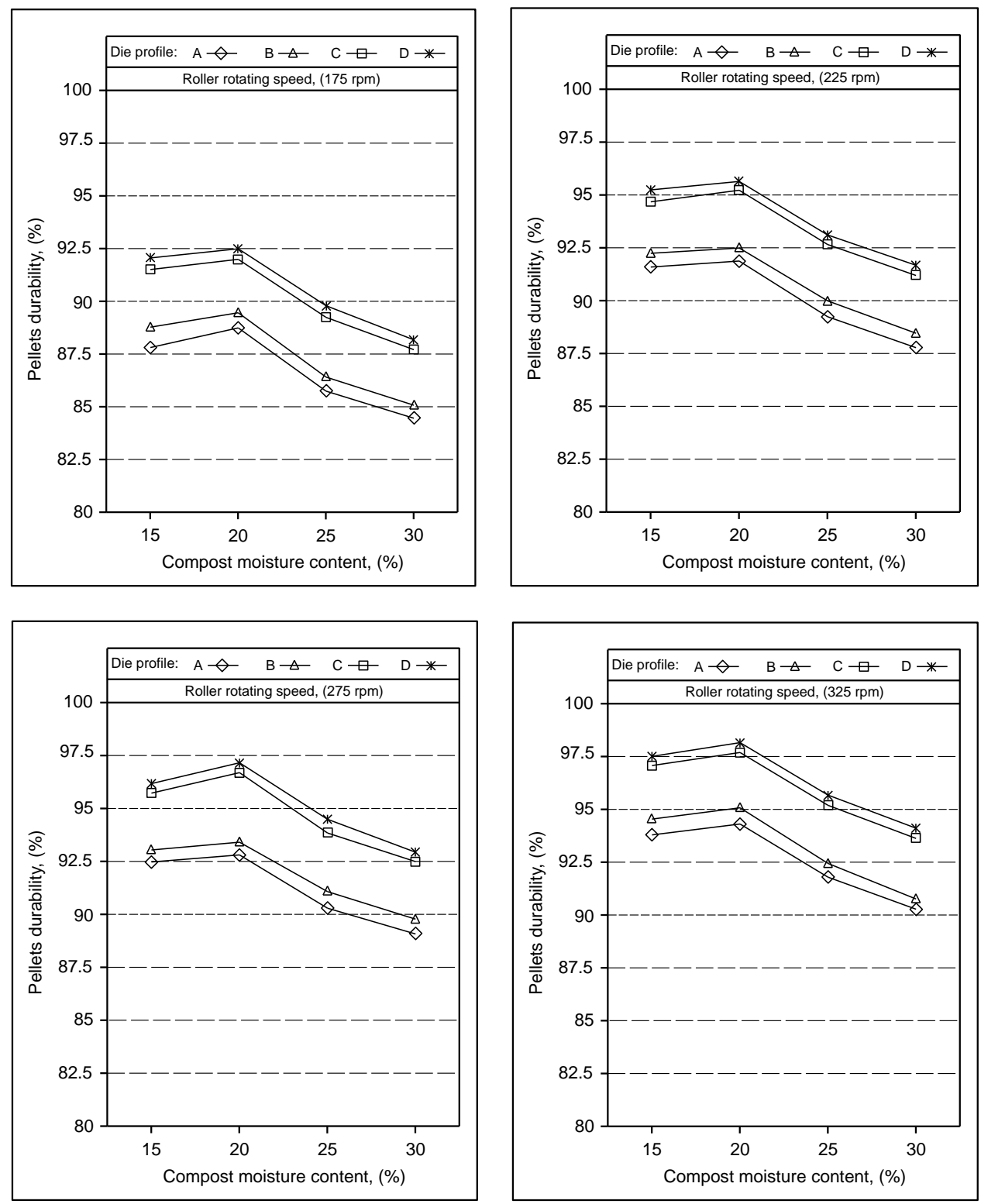

Fig.6. Effect of compost moisture content on pellets durability using different die profiles under different rollers rotating speeds. 
The increase in pellets durability by changing the die profile from die (A) to (B), (C) and (D) could be due to the increase in die hole land length and die hole entry diameter, that produce high compact pellets and increase the pellets hardness so increase the pellets durability.

\subsubsection{Effect of roller rotating speed:}

Data in Fig. 6 show that, increasing the rollers speed from 175 to 225, 275 and $325 \mathrm{rpm}$ increased the pellets durability by $3.73 \%, 4.81 \%$ and $6.21 \%, 3.71 \%$, $4.77 \%$ and $6.17 \%, 3.82 \%, 4.92$ and $6.35 \%$ and by $3.88,4.99$ and $6.45 \%$ using die (A) by 3.60, 4.63 and 5.99\%, 3.57\%, 4.60\% and. 3.95\%, 3.67\%, $4.73 \%$ and $6.12 \%$ and by $3.73 \%, 4.81 \%$ and $6.21 \%$ using die profile (B) by $3.70,4.77$ and $6.15 \%, 3.68,4.73$ and $6 \% .12,3.78,4.87$ and $6.30 \%$ and by $3.85,4.95$ and $6.40 \%$ using die profile (C) by 3.58, 4.61 and 5.96\%, 3.56, 4.58 and 5.93\%, 3.66, 4.72 and $6.09 \%$ and by $3.72,4.79$ and $6.19 \%$ using die profile (D) under compost moisture content of 15, 20, 25 and $30 \%$, respectively. The increase in pellets durability by increasing the roller speed from 175 to 225,275 and $325 \mathrm{rpm}$ could be due to the high correlation between the compost granules by high raw material compact time that make the pellets output more compacted and decrease the pellets cracks.

\subsection{Effect of some engineering and operating parameters on disk pelleter energy requirements:}

\subsubsection{Effect of compost moisture content:}

Fig.7 indicates that increasing compost moisture content from 15\% to 20, 25 and $30 \%$ increased the energy requirements by $2.04,33.22$ and $49.65 \%$ using die profile (A) by $0.72,23.59$ and $39.03 \%$ using die profile (B) by $2.95,38.77$ and $55.30 \%$ using die profile (C) and by 1.11,26.76 and $42.69 \%$ using die profile (D) at roller speed of $175 \mathrm{rpm}$, by $1.81,31.06$ and $47.13 \%$ using die profile (A) by0.76, 22.49 and $37.45 \%$ using die profile (B), by $2.53,35.84$ and $52.16 \%$ using die profile (C) and by 1.01, 25.35 and $40.83 \%$ using die profile (D), under roller speed of $225 \mathrm{rpm}$, by $1.31,26.90$ and $42.31 \%$ using die profile A, by $0.49,20.33$ and $34.60 \%$ using die profile B, by $1.76,30.32$ and $46.14 \%$ using die profile (C) and by $0.75,22.59$ and $37.36 \%$, using die profile (D) under roller speed of $275 \mathrm{rpm}$, and by 1.02, 24.08 and $38.83 \%$ using die profile (A) by 0.39 , 18.73 and $32.38 \%$ using die profile (B) by 1.35, 26.74 and $41.93 \%$ using die profile (C) and by $0.59,20.61$ and $34.72 \%$ using die profile (D) under roller speed of $325 \mathrm{rpm}$. The increase in energy requirements by increasing compost moisture content from $15 \%$ to $20 \%$ could be due to the high increase in 
treatment power consumed with low increase in production rate, and the high increase in treatment power consumed with decrease in production rate by increasing the compost moisture content from $15 \%$ to 25 and $30 \%$.
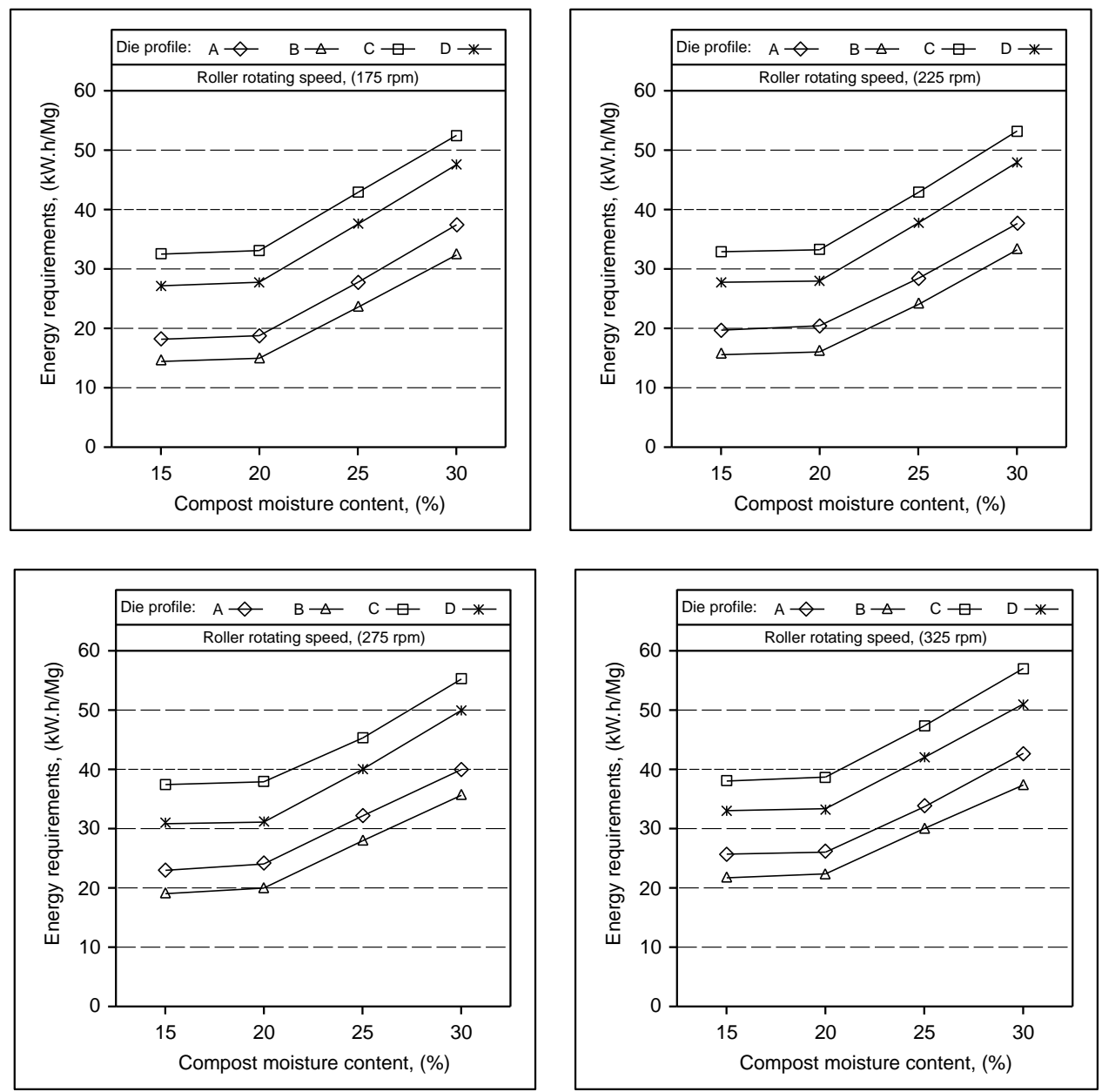

Fig.7. Effect of compost moisture content on energy requirement using different die profiles under different rollers rotating speeds.

\subsubsection{Effect of die profile:}

Results in Fig.7 shows that changing the die holes profile from die (A) to die (B) and die (D) increased the energy requirements by 42.68 and $30.72 \%$ at compost moisture content of $15 \%, 41.90$ and $30.06 \%$ at compost moisture content of $20 \%, 34.41$ and $24.01 \%$ at compost moisture content of $25 \%$ and 30.59 and $31.15 \%$ at compost moisture content of $30 \%$, and 40.26 and $28.66 \%$ at compost moisture content of $15 \%, 39.56$ and $28.09 \%$ at compost moisture content of $20 \%, 32.83$ and $22.57 \%$ at compost moisture content of $25 \%$ and 29.32 and 
$20.16 \% \%$ at compost moisture content of $30 \%$, and 35.45 and $24.75 \%$ at compost moisture content of $15 \%, 34.91$ and $24.33 \%$ at compost moisture content of $20 \%, 29.64$ and $20.32 \%$ at compost moisture content of $25 \%$ and 26.82 and $18.29 \%$ at compost moisture content of $30 \%$, and 32.10 and $22.13 \%$ at compost moisture content of 15\%, 13.66 and $21.79 \%$ at compost moisture content of $20 \%, 27.32$ and $18.57 \%$ at compost moisture content of $25 \%$ and 24.93 and $16.90 \%$ at compost moisture content of $30 \%$ under roller speeds of 175, 225, 275 and $325 \mathrm{rpm}$, respectively. The increase in energy requirements by changing the die holes profile from (A) to B and (D) could be due to the increase in die hole land length, that increase the compost raw material retention time in the die hole, and increase the machine load that increase the power consumed and decrease the pelleter productivity.

Meanwhile, changing the die holes profile from die (A) to die (C) decreased the energy requirements by $29.48,28.28,18.72$ and $14.94 \%$ using roller speed of $175 \mathrm{rpm}, 25.9725 .04,17.25$ and $13.99 \%$ at roller speed of $225 \mathrm{rpm}, 20.08$, $19.52,14.46$ and12.12\% at roller speed of $275 \mathrm{rpm}$, and 16.77, 16.38, 12.68 and $4.15 \%$ at roller speed of $325 \mathrm{rpm}$, under compost moisture contents of 15, 20, 25 and 30\%, respectively. The decrease in energy requirements by changing the die profile from die $\mathrm{A}$ to die $\mathrm{C}$ could be due to the increase in die hole entry diameter, that make the compost raw material flow through the die hole easily, with decrease in formula retention time in the die hole, that decrease the machine load and power consumed with slow increase in pelleter productivity.

\subsubsection{Effect of roller rotating speed:}

Data in Fig. 7 shows that, increasing rollers speed from 175 to $225 \mathrm{rpm}$ increased the energy requirements by $4.33,4.10$ and $1.24 \%$ and decreased the energy requirement by $0.45 \%$ using die profile (A) by 0.29 and $0.24 \%$ and decreased the energy requirements by1.14 and 2.28\% using die profile (B), 6.92, $6.52,2.46$ and $0.37 \%$ using die profile (C) and by 1.49 and $1.40 \%$ and decreased the energy requirements by 0.39 and $1.68 \%$ using die profile (D) under compost moisture content of 15,20, 25 and 30\% respectively. The increase in energy requirements by increasing rollers speed from 175 to $225 \mathrm{rpm}$ under moisture contents of 15 and $20 \%$ could be due to the increase in machine consumed power, while the decrease in energy requirements under compost moisture content of 25 and $30 \%$ could be due to the increase in pelleter productivity under this level of moisture. While increasing the roller speed from 175 to 275 and 325 rpm increased the energy requirements by 19.19 and $27.21 \%, 18.58$ and $26.45 \%$, 
11.53 and $17.25 \%$ and 7.41 and 11.58 using die profile (A) 9.00 and $13.78 \%$, 8.79 and $13.50 \%, 5.11$ and $8.30 \%$ and 2.38 and $4.37 \%$ using die profile (B), 25.05 and $34.36 \%, 24.14$ and $33.28 \%, 14.70$ and $21.46 \%$ and 9.68 and $14.73 \%$ using die profile (C) and by 12.23 and $18.19 \%, 11.91$ and $17.76 \%, 7.24$ and $11.33 \%$ and 4.06 and $6.81 \%$ using die profile (D) under compost moisture content of 15, 20, 25 and 30\%, respectively. The increase in energy requirements by increasing the rollers rotating speed from 175 to 275 and 325 rpm could be due to the high increase in power consumed by motor load with low increase in machine pelleter productivity.

\subsection{Effect of some engineering and operating parameters on disk pelleter compost operational cost per mass unit:}

\subsubsection{Effect of compost moisture content:}

Data in Fig. 8 shows that increasing the compost moisture content from $15 \%$ to 20 , decreased the cost per mass unit by $0.07,0.17,0.04$ and $0.13 \%$ at roller speed of $175 \mathrm{rpm}$, by $0.06,0.14,0.03$ and $0.11 \%$ at roller speed of $225 \mathrm{rpm}$, by $0.06,0.15,0.04$ and $0.11 \%$ at roller speed of $275 \mathrm{rpm}$, and by 0.07, 0.14, 0.04 and $0.11 \%$ at roller speed of $325 \mathrm{rpm}$ under dies profiles of (A, B, C and D), respectively. The very slow decrease in cost per mass unit by increasing the compost moisture content from $15 \%$ to $20 \%$ could be due to the slow increase in pelleter productivity. While increasing the compost moisture content from $15 \%$ to 25 and $30 \%$ increased the cost per mass unit by 5.88 and $12.22,5.83$ and $12.50,5.94$ and 12.22 , and 5.90 and 12.51 at roller speed of $175 \mathrm{rpm}$, by 5.60 and $11.58,5.55$ and 11.83, 5.65 and 11.58, and 5.61 and 11.84 at roller speed of $225 \mathrm{rpm}$, by 5.34 and 11.07, 5.29 and 11.31, 5.38 and 11.08 , and 5.35 and 11.31 using roller speed of $275 \mathrm{rpm}$ and by 5.07 and 10.53, 5.03 and 10.74, 5.12 and 10.54, and 5.08 and 10.75 at roller speed of $325 \mathrm{rpm}$ under dies profiles of (A, B, $\mathrm{C}$ and $\mathrm{D})$, respectively. The high increase in cost per mass unit by increasing the compost moisture content from $15 \%$ to $30 \%$ could be due to the high decrease in pelleter productivity and the increase in power consumption, that increasing the cost per time unit.

\subsubsection{Effect of die profile:}

Results in Fig. 8 shows that changing the die holes profile from die (A) to die (B) and die (D) increased the cost per mass unit rate by 8.42 and $5.43 \%$ at compost moisture content of $15 \%, 8.33$ and $5.37 \%$ at compost moisture content of $20 \%, 8.37$ and $5.45 \%$ at compost moisture content of $25 \%$ and 8.72 and $5.75 \%$ using compost moisture content of $30 \%$, and by 8.03 and $5.17 \%$ at compost 
moisture content of $15 \%, 7.94$ and $5.11 \%$ at compost moisture content of $20 \%$, 7.98 and $5.18 \%$ at compost moisture content of $25 \%$ and 8.29 and $5.45 \%$ at compost moisture content of 30\%, and by 7.65 and $4.93 \%$ at compost moisture content of $15 \%, 7.58$ and $4.88 \%$ at compost moisture content of $20 \%, 7.61$ and $4.94 \%$ at compost moisture content of $25 \%$ and 7.89 and $5.18 \%$ at compost moisture content of $30 \%$, and by 7.28 and $4.68 \%$ at compost moisture content of $15 \%, 7.21$ and $4.64 \%$ at compost moisture content of 20\%, 7.24 and $4.70 \%$ using compost moisture content of $25 \%$ and 7.50 and $4.91 \%$ at compost moisture content of $30 \%$ under roller speeds of 175, 225, 275 and $325 \mathrm{rpm}$, respectively.
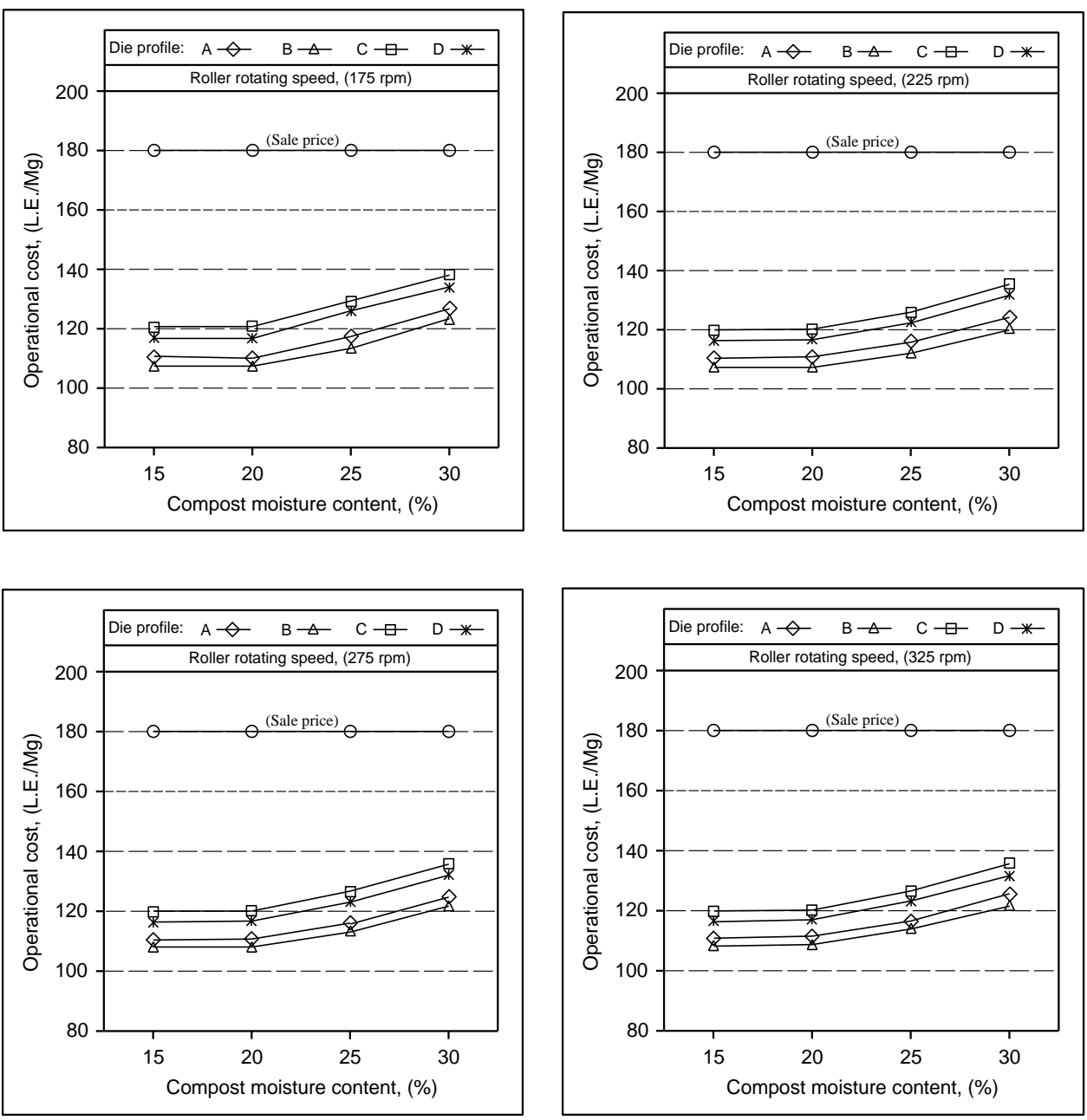

Fig.8. Effect of compost moisture content on cost per mass unit using different die profiles under different rollers rotating speeds. 
The clear increase in compost pellet cost per mass unit by changing the die holes profile from die (A) to die (B) and die (D) could be due to the increase in die holes land length, that reduce the compost pelleter productivity, with increase in power consumption. On the other hand, changing the die holes profile from die (A) to die (C) decreased the compost pellets cost per mass unit by $2.69,2.66,2.62$ and $2.68 \%$ at roller speed of $175 \mathrm{rpm}, 2.56,2.53,2.50$ and $2.55 \%$ using roller speed of $225 \mathrm{rpm}, 2.42,2.4,2.37$ and $2.41 \%$ at roller speed of $275 \mathrm{rpm}$, and by 2.29, 2.27, 2.25 and $2.3 \%$ at roller speed of $325 \mathrm{rpm}$, under compost moisture content of 15,20,25 and 30\%, respectively. The slow decrease in compost pellets cost per mass unit by changing the die profile from die (A) to die (C) could be due to the increase in die hole entry diameter, that increase slowly the pelleter productivity, so decrease the cost per mass unit.

\subsubsection{Effect of roller speed:}

Fig. 8 showed that increasing rollers speed from 175 to $225 \mathrm{rpm}$ decrease the cost per mass unit by $0.89,0.88,1.20$ and $1.62 \%$ using die profile (A) 1.33, $1.31,1.63$ and $2.10 \%$ using die profile (B) $0.77,0.76,1.08$ and $1.49 \%$ using die profile (C) and 1.18, 1.16, 1.49 and 1.95\% using die profile (D) under compost moisture contents of 15,20,25 and 30\%, respectively. The decrease in compost pellets cost per mass unit by increasing the rollers speed from 175 to $225 \mathrm{rpm}$ under all the moisture content levels could be due to the increase in pelleter productivity by increasing the roller speed. While increasing the roller speed from 175 to $275 \mathrm{rpm}$ increased the cost per mass unit by 0.19 and $0.20,0.46$ and $0.45 \%$ at compost moisture content of 15 and $20 \%$, and decreased the cost per mass unit by 0.38 and $1.10,0.14$ and $0.84 \%$ at compost moisture content of 25 and $30 \%$ under die profile (A) and die profile (C), respectively. Meanwhile increasing the roller speed from 175 to $325 \mathrm{rpm}$ increased the cost per mass unit by 0.56 and $0.57,0.94$ and $0.93 \%$ at compost moisture content of 15 and $20 \%$, and decreased the cost per mass unit by 0.29 and $1.33,0.16$ and $0.95 \%$ at compost moisture content of 25 and 30\% under die profile (A) and die profile (C), respectively. The increase in cost per mass unit by increasing roller speed from 175 to $275 \mathrm{rpm}$ under compost moisture content of 15 and $20 \%$ and die profile (A) and (B) could be due to the increase in power consumed by increasing the roller speed with low increase in pelleter productivity. On the other side, increasing the rollers speed from 175 to 225 decreased the cost per mass unit by $0.64,0.62,1.22$ and $2.01 \%$ using die profile of (B) and $0.34,0.32$, 0.92 and $0.71 \%$ using die profile (D) under compost moisture contents of 15,20 , 
25 and 30\%, respectively. Increasing the rollers speed from 175 to 325 decreased the cost per mass unit by $0.67,0.64,1.53$ and $2.69 \%$ using die profile (B) and $0.22,0.20,1.09$ and $2.23 \%$ using die profile (D) under compost moisture contents of 15, 20, 25 and 30\%, respectively. The decrease in compost pellets cost per mass unit by increasing the rollers speed from 175 to $325 \mathrm{rpm}$ under all the moisture content levels could be due to the increase in pelleter productivity by increasing the roller speed.

\section{CONCLUSION}

The important results as mentioned in the obtained data were summarized in the following: The optimum rollers rotating speed of disk pelleter was $275 \mathrm{rpm}$ for high machine efficiency (machine productivity and energy requirements) and pellets quality. To obtain the best machine performance, the compost raw material moisture content must be about $20 \%$. The best die profiles (die holes dimension) were (B) (20.3 mm land length with $13.5 \mathrm{~mm}$ entry diameter) and die (D) (20.3 mm land length with $14.2 \mathrm{~mm}$ entry diameter). The highest pelleter productivity was $302.4 \mathrm{~kg} / \mathrm{h}$ using roller rotating speed of $325 \mathrm{rpm}$, compost moisture content of $20 \%$ and die profile (C) $(18.8 \mathrm{~mm}$ land length with $14.2 \mathrm{~mm}$ entry diameter). The lowest energy requirement were $14.58 \mathrm{~kW} . \mathrm{h} / \mathrm{Mg}$ using roller rotating speed of $175 \mathrm{rpm}, 15 \%$ moisture content and die profile (C) (18.8 $\mathrm{mm}$ land length with $14.2 \mathrm{~mm}$ entry diameter). The highest pellets durability was $98.12 \%$ at roller rotating speed of $325 \mathrm{rpm}, 20 \%$ moisture content and die profile (D) (20.3 mm land length with $14.2 \mathrm{~mm}$ entry diameter). The low cost per mass unit of compost pellets was $107.01 \mathrm{~L} . \mathrm{E} / \mathrm{Mg}$ at rollers rotating speed of $225 \mathrm{rpm}, 20 \%$ moisture content and die profile (C) $(18.8 \mathrm{~mm}$ land length with $14.2 \mathrm{~mm}$ entry diameter).

\section{REFERENCES}

Abou-Akkada, R. A. and A. M. Niur. (1985): By product utilization in Egypt. A proposed strategy for the development of animal feed resource ARNAP working shop 14-18 Oct 1985, Alex. Egypt.

Awady, M. N. (1978): Tractor and farm machinery. Text book, Faculty of Agriculture, Ain-Shams University. Pp: 164-167.

Awady, M. N; E. Y. Ghoneim and A. I. Hashish (1982): A critical comparison between wheat combine harvester under Egyptian conditions. R. S. No. 1920, Ain-Shams University. (FAO) J.

Bhienki, K. (2000): Factors influencing pellet quality. Department of grain science and industry. Manhattan Kansas state Univ. USA 66506-2201. 
David, A. F. (2003a): Pelleting for profit-part. National Grain and feed association. Feed and feeding digest. Vol.54, No. 6, November 13.

David, A. F. (2003b): Pelleting for profit-part2. National Grain and feed association. Feed and feeding digest, Vol. 54 No. 7 December 22.

Greer, D. and J. Fairchild (1999): Cold mash moisture control boosts pellet quality. Feed management, Vol. 50 No. 6, Watt publishing company, 14t. Marris, 111.

Hara, M. (2005): Fertilizer pellets made from composted livestock manure. Mie prefectural science and technology promotion center, Kawasakita 530. Uresinochou, Itisigun 515-2316 Japan.

Hasting W. H. (2003): Feed milling process. Mt. Vernon, Washington D. Higgs Environment Canada, Van cover, Britich Columbia.

Ismael, N. (2001): Engineering studies on the processing of some agricultural wastes. Ph. D Thesis Fac. of Agric. Eng. Dept. Mansoura Univ. Egypt.

Jennifer, M. (2004): Physical characteristics of pellets from poultry litter. ASAE/ CSAE annual international meeting sponsored by ASAE/ CSAE. Fairmont. Chateau laurier. The Westin, Government center. Ottawa, Ontario, Canada 1-4 August 2004.

Kaddour, U.A; T. A. Ewies and M. K. Afify (2006): Influence of Geometrical dimension of extrusion die holes on machine efficiency and pellets quality. 4th annual conference of J. Agric. Sci. Mansoura Univ., 2006, 31 (7): 337358.

Nour, A. M. (1988): By-product utilization in Egypt. A proposed strategy for the development of animal feed resource ARNAP workshop, 14-18 October 1985 Alex. Egypt, 131-150.

Shehab, S; S. Mani, X. Bi, P. Zaini and L. Tabil (2005): Binder less pelletization of Biomass Sponsored by ASAE. Tampa convention center. Tampa, Florida, 17-20 July 2005.

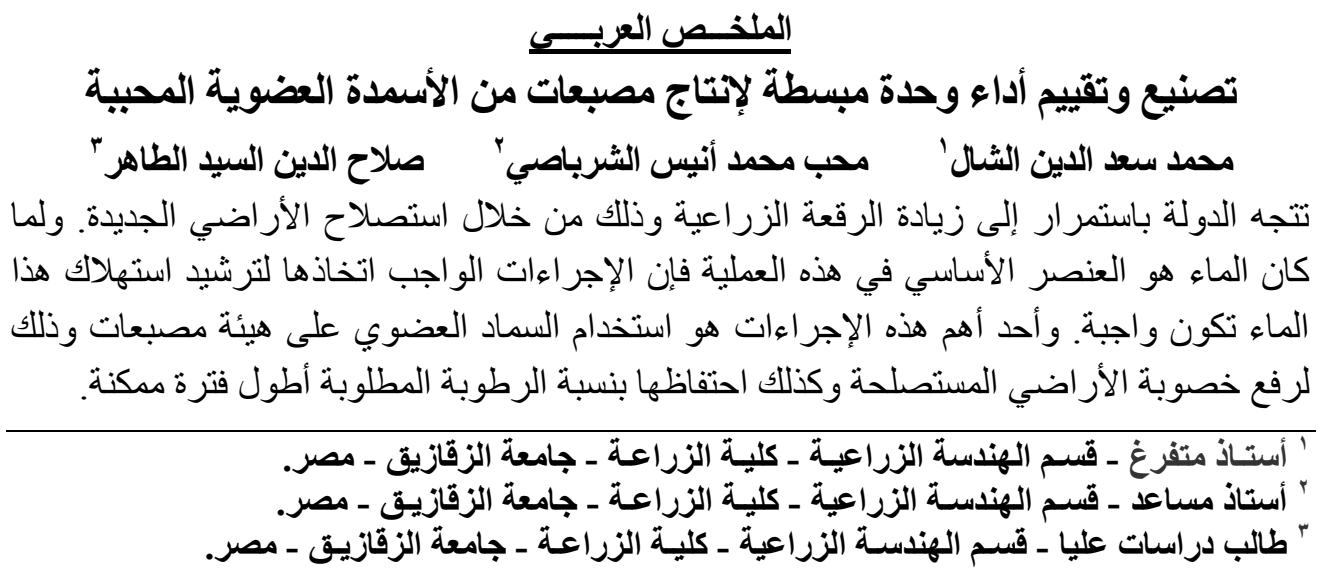


وتهدف هذه الدراسة إلى كبس السماد العضوي (الكمبوست) في صورة مصبعات بهدف زيادة السعة

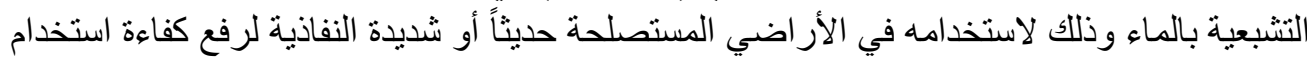

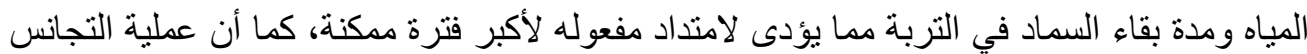

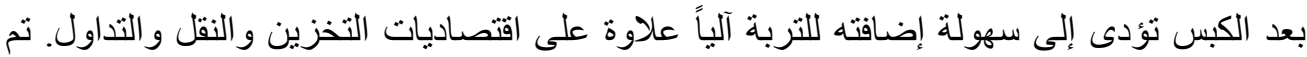
تصنيع وحدة مبسطة بخامات محلية وذللك لكبس السماد العضوي على الكى هيئة مصبعات الكيات ، وتتكون هذه

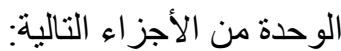

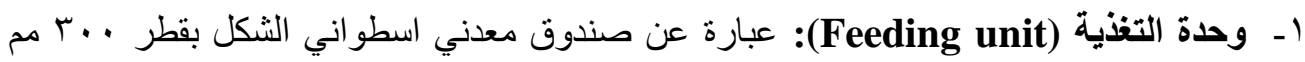

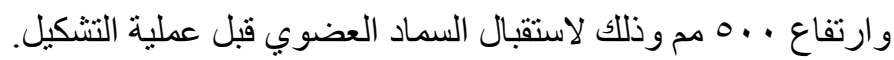

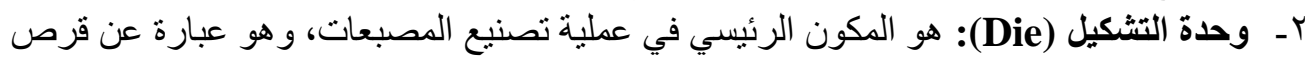

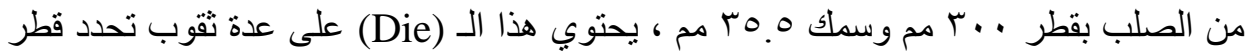

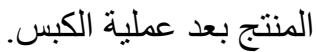

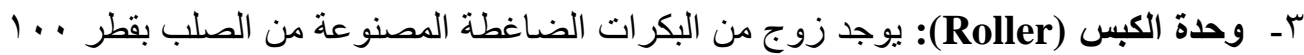

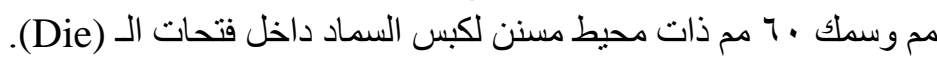

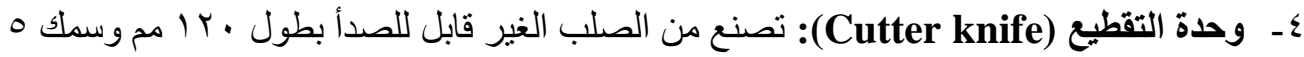

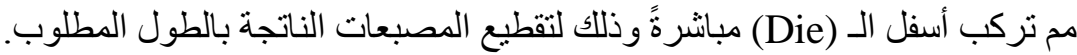

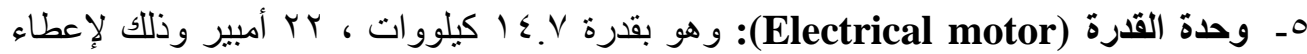
السر عة الدور انبة للبكر ات الضاغطة. وكانت عوامل الاراسة هي: الأني

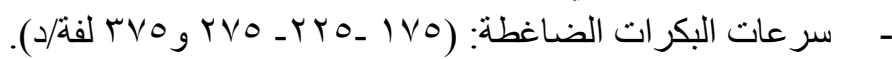
-

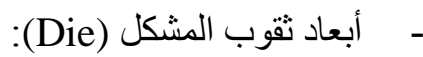

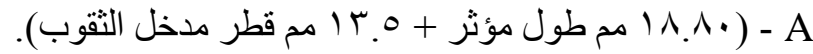

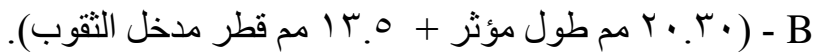

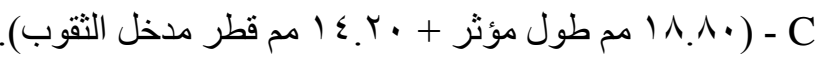

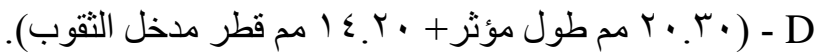
وكانت أفضل النتائج المتحصل عليها كالأتي: لاع Y YV.V9

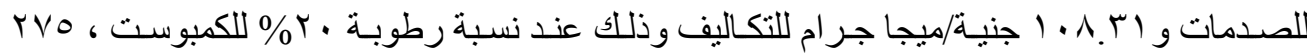

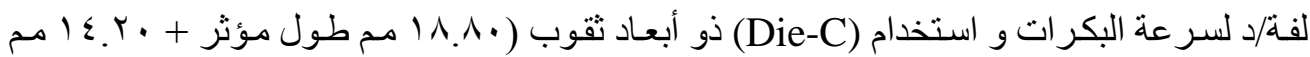

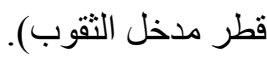

